\title{
TRANS GENDERS: An Analysis of their Body, Mind and Culture
}

\author{
Dr. Madhusudhan. $\mathrm{S}^{1}$, Vaniprabha G. $\mathrm{V}^{2 *}$
}

\section{ABSTRACT}

A transgender individual may have characteristics that are normally associated with a particular gender and identify elsewhere on the traditional gender continuum, or exist outside of it as other, age, gender neutral third gender etc. Furthermore, many transgender people experience a period of identity development that includes better understanding one's self-image, self-reflection, and self-expression. More specifically, the degree to which individuals feel genuine, authentic, and comfortable within their external appearance and accept their genuine identity is referred to as transgender congruence. This study explored these factors of body, mind and their culture among this population in Bengaluru, India

Keywords: Transgender, Hormonal Therapy, Psychotherapy, Mind Body Culture,

Transgender people experience a mismatch between their gender identities their gender expression and their assigned sex. The definition of Transgender includes:

"Of, relating to, or designating a person whose identity does not conform unambiguously to conventional notions of male or female gender roles, but combines or moves between these." People who were assigned a sex, usually at birth and based on their genitals, but who feel that this is a false or incomplete description of themselves."Non-identification with, or nonpresentation as, the sex (and assumed gender) one was assigned at birth[12].”

\section{Sex or Gender}

The Medilexicon Medical dictionary states that one's sex is a biological or physiological quality, while one's gender is a (psychological) "category to which an individual is assigned by self or others[1]. Trans sexuality can be said to deal more with material aspects of one's sexuality Transgender said to deal more with one's internal gender disposition or predisposition, as well as the related social expectations that may accompany a given gender role.

A small percentage of the population believes so strongly that they were born the "wrong" sex that they seek surgical and hormonal treatment [9]. This treatment effectively changes the physical sexual characteristics of this individual to the opposite gender. Estimates based on

\footnotetext{
${ }^{1}$ Asst. Prof Dept of Psychiatry, BMCRI

${ }^{2}$ Clinical Psychologist, BMCRI

*Corresponding Author

(C) 2015 I S Madhusudhan, G Vaniprabha; licensee IJIP. This is an Open Access Research distributed under the terms of the Creative Commons Attribution License (http://creativecommons.org/licenses/by/2.0), which permits unrestricted use, distribution, and reproduction in any Medium, provided the original work is properly cited.
} 
referrals indicate that at least one out of every thirty thousand males and one out of every one hundred thousand females desire some type of transsexual treatment[10].

The ICD-10 now provides five diagnoses for the gender identity disorders (F64):[12]

1. Transsexualism (F64.0)

2. Dual-role Transvestism

3. Gender Identity Disorder of Childhood

4. Other Gender Identity Disorders (F64.8

5. Gender Identity Disorder, Unspecified

Transsexualism (F64.0) has three criteria

The desire to live and be accepted as a member of the opposite sex, usually accompanied by the wish to make his or her body as congruent as possible with the preferred sex through surgery and hormone treatment. The transsexual identity has been present persistently for at least two years. The disorder is not a symptom of another mental disorder or a chromosomal abnormality.

\section{Harmonal Therapy}

The treatment of a transsexual with hormones is equally difficult.[2] Upsetting the delicate balance of one's hormones may result in several types of difficulties. These include liver abnormalities, reduction of libido, elevated triglycerides, increased rate of breast cancer, cerebral thrombosis, and pulmonary embolism for birth males. While there are many side effects of hormone treatment, administration of hormonal levels similar to those of the opposite gender has the advantage of beginning the process for change. The masculine features of the male soften to become more feminine; the feminine features of the female develop a more masculine appearance[3].

\section{Surgical Intervention}

Most research indicates that almost eighty percent of those receiving transsexual surgery are satisfied with the overall outcome and with only two percent regretting their change of sex . Gender is a complicated issue for the living organism. It involves functional anatomy or physical structure and a complicated system of various hormones.

While structure may be easily changed, it is desirable to transform sex organs so that they are capable of producing sexual pleasure. This is not always an easy task. Some risk associated with the physical alteration of gender, new surgical techniques have greatly reduced the possibility of destroying the ability to experience sexual pleasure.

\section{Surgical procedures may include}

Orchiectomy, Penectomy, Vaginoplasty, Augmentation mammaplasty, and Vocal cord surgery. 
High costs of such treatment, generally not covered by any type of medical insurance, also may prohibit individuals from seeking treatment. Those who receive treatment face physical problems, periods of psychological adjustment, social or culture problems.

The purpose of this paper is to review these elements with regard to transsexual surgery.

\section{Design}

This longitudinal study was conducted at a Tertiary General hospital, Bangalore, India.

40 Subjects of which 30 were male and 10 were female Referred from Plastic surgery department to psychiatry who wanted to undergo surgery to change their sex were taken up for the study.

\section{HYPOTHESIS}

- There will be a significant difference in the body image, gender role definition (body), self esteem (mind) and cultural norms among transgender pre and post surgery.

\section{Inclusion Criteria}

- Written consent was taken from all the subjects.

- Women and Men above the age of 18 years.

\section{Exclusion Criteria}

- Women and Men should not have any other physical or psychological co-morbidities

\section{METHODOLOGY}

Tools

- An ICD -10 classification of Gender Identity Disorder.

- A semi structured interview with Harry Benjamin SOC was considered to understand their socio-demography and culture.[7]

- Derogatis sexual Functioning Inventory(DSFI) [5]

- Self Esteem Inventory by Mackinnon (1985)

\section{Derogatis sexual Functioning Inventory(DSFI) [5]}

A multi-dimensional measure of current level of sexual functioning. The Global Sexual Satisfaction Index (GSSI), is Self-administered it reflects subjective perception of sexual behaviour. Quality of sexual functioning is represented on a 9-point scale ranging from 0 (could not be worse) to 8 (could not be better). 254 items arranged into 10 sub-tests. Each sub-test measures a specific aspect of sexuality: Information on sexuality, Participant's sexual experience, Attitude toward sexual activity and relationships, Sexual drive, Psychological symptoms, affect, Gender role definition, Sexual fantasies, body image, and sexual satisfaction 


\section{Eligibility and Readiness Criteria}

30 Male and 10 female above the age of 18 years approached the Dept of Plastic surgery for surgery to change their sex. Psychotherapy for a period of 3 months which is the minimum was done. Real life experiences for a period of 12 months[5] They were administered Hormone therapy for a period of 12 months as per SOC simultaneously

\section{Psychotherapy}

Knowledge of the cost, length of stay in hospital, likely complications and post Surgical Rehabilitation requirements of various surgical procedures. Demonstrable progress in dealing with work, family, and interpersonal issues resulting in a significantly better or at least a stable state of mental health[7].

\section{Real Life Experience}

All of the subjects narrated experiences from their early childhood that they did feel uncomfortable with themselves and their bodies [8]. They loved to wear dresses of the opposite sex, they recall incidence of being beaten up by their parents. Mothers crying for their Inappropriateness. Multi number of visits to Religious places. Counselling by any and all they knew.

\section{Pre Surgical Assessment}

A Self Esteem Inventory by Mackinnon (1985) was administered [8].

Harry Benjamin SOC[7] indicated their strong desire for sexual change The Tools that were administered showed a strong Desire to undergo surgery After the parameters were fulfilled they were referred to the Department of Plastic surgery for the further needful.

\section{Surgical Procedures}

Females underwent- Mastectomy and penis reconstruction and Males - Castration and Breast Reconstruction Total duration of hospital stay was 3 to 4 months

Follow up during this period i.e., 4 months indicated that Their Morale had boosted and they felt more Relaxed and "IN PLACE". Their Self Esteem had improved leaps and Bounds Their Sexual Orientation also had the right perspective

\section{RESULTS}

The socio demography of the subjects revealed they were from above average to High socio economic status. Educational Status: Of the 40 people, 23 had completed Post graduation level of education and 17 had a B.E degree. Child Order: They were the only child in the family, they had no siblings. Religiosity: They were not religious in nature and Family Culture: had a very liberal family culture. About $\mathbf{3 2}$ of them had single parent predominantly mother 
Table I, Indicates the Self Esteem Pre and Post Surgery Scores of Male and Female

\begin{tabular}{|l|l|l|}
\hline \multicolumn{3}{|c|}{ MALE TO FEMALE } \\
\hline Pre surgery & Post surgery & Max \\
\hline 24 & 55 & 60 \\
\hline
\end{tabular}

\begin{tabular}{|l|l|l|}
\hline \multicolumn{2}{|c|}{ FEMALE TO MALE } \\
\hline Pre surgery & Post surgery & Max \\
\hline 14 & 48 & 60 \\
\hline
\end{tabular}

GSSI of DSFI reflects subjective perception of sexual behaviour.

- Quality of sexual functioning is represented on a 9-point scale ranging

- Description of scores: 0 (could not be worse) to 8 (could not be better)

Table II Indicates The GSSI Scores Of Global Sexual Satisfaction Index (GSSI) of Male and Female Pre and Post Surgery.

\begin{tabular}{|l|l|l|l|}
\hline \multicolumn{5}{|c|}{ Global Sexual Satisfaction Index (GSSI) } \\
\hline PRE SURGERY & SCORE & POST SURGERY & SCORE \\
\hline Male to Female & 0 & Male to Female & 8 \\
\hline Female to Male & 0 & Female to Male & 8 \\
\hline
\end{tabular}




\section{Body and Mind}

After the surgical procedure their sex role orientation and their Body had reached the desired goal as expressed by them. They felt relieved that they had finally found what they were looking for since birth.

\section{Culture}

They were a part of the major society they belonged to due to their birth and followed what was being practised in their family not very culture bound.Now they belonged to a new community the "TRANSGENDER COMMUNITY" which had it's own rule and regulations not very stringent (as reported by them).

SANGAMA an NGO welcomed them, they are given new identities, they had to follow customs as followed by their new family. They worship MATHAJI a deity of their clan.

\section{Transformation}

A new leap of change in their Body, Mind and culture was noticed [6] and The level of satisfaction for having achieved the unachievable was beaming in their eyes. They started to live along with their fellow transgender rather than with their family. They continued their profession they were into earlier to their surgery. About 16 of them married their partners who they had already convinced before the surgery.

\section{DISCUSSION}

There was a significant difference in the body image, gender role definition (body), self Esteem (mind) and cultural norms among transgender pre and post surgery.

A new transformation moved them from a confused state to a state of ecstasy and firm belief of achievement, there was no more confusion. “A HAPPY BEGINNING” as reported by them.

There will be a significant difference in the Body image, gender role definition (body), Self Esteem (mind) and cultural norms among transgender pre and post surgery. The Psychotherapy that was done during the transformation years helped them in coping up with their internal conflicts.

\section{CONCLUSION}

This study enhanced the hypothesis that there is significant difference in the Body image, gender role definition (body), Self Esteem (mind) and cultural norms among transgender pre and post surgery. Self Esteem scores post surgery was significantly increased in both the groups.

4 months follow up showed a significant high self esteem and sexual. 


\section{LIMITATIONS}

The sample was mainly from the urban areas and those who were referred to the Out patient unit of the psychiatry department.

\section{DISCLAIMER}

There was no funding received for this study from any agency.

\section{REFERENCES}

1. Andersen BL, lachen brunch PA etal: Sexual Dysfunction and signs of gynaecological cancer. Cancer 57:1880,1886,1986.

2. Bentler PM: Heterosexual behaviour assessment, I; Males Behav Res Ther 6:21-25, 1968 a.

3. Bentler PM: Heterosexual behaviour assessment, II; Females Behav Res Ther 6:27-30, 1968 b.

4. Clayton AH, Mc Garvey et al: Comparison on sexual functioning in clinical and nonclinical populations using the changes in Sexual Functioning Questionnaire. Psychopharmacol Bull 33:731-745,1997 a.

5. Derrogatis LR: Derrogatis Sexual Functioning Inventory (DSFI): Preliminary Scoring. Baltimore, MD, Clinical Psychometric Research, 1975

6. Fisher, T. D., Davis, C. M., Yarber, W. L., \& Davis, S. L. (2010). Handbook of SexualityRelated Measures. New York: Routledge.

7. Harry Benjamin International Gender Dysphoria association's The standards of care for gender identity disorders(Fifth Version) 1990.

8. Mackinnon Self Esteem Inventory 1985 Handbook of Psychiatric measures2nd Edn, Rush first Blacker,1995.

9. National AIDS Control Programme, Country Scenario Update Published by Ministry of Health and Family Welfare, National AIDS Control Organization, Government of India, 1991.

10. Patel V, Kirkwood BR, Pednekar S, et al. Gender disadvantage and reproductive health risk factors for common mental disorders in women: a community survey in India. Arch Gen Psychiatry. 2006;63:404-413.

11. Rao, V., I. Gupta, M. Lokshin, and S. Jana. 2003. "Sex Workers and the Cost of Safe Sex: The Compensating Differential for Condom Use Among Calcutta Prostitutes.” Journal of Development Economics 71(2003): 585-603.

12. The ICD 10 Classification of Mental and Behavioral Disorders WHO Geneva, 2002. 